\title{
AN EVALUATION OF HEALTH RELATED QUALITY OF LIFE IN PATIENTS WITH RHEUMATOID ARTHRITIS
}

G.O. Oyoo, MBChB, MMed, Cert Rheumatology, FACR, FRCP (Edin), Consultant Physician and Rheumatologist, Senior Lecturer, Department of Clinical Medicine and Therapeutics, School of Medicine, University of Nairobi, P. O. Box 19701-00202, Nairobi, Kenya, B.O. Owino, MBChB, MMed, Cosultant Physician and Rheumatologist, Kenyatta National Hospital. P. O. Box 20723-00202, Nairobi, Kenya and C.F. Otieno, MBChB, MMed, Consultant Physician and Endocrinologist, Associate Professor, Department of Clinical Medicine and Therapeutics, School of Medicine, University of Nairobi, P. O. Box 19676-00202, Nairobi, Kenya

Correspondence to: Dr. G.O. Oyoo, Department of Clinical Medicine and Therapeutics, School of Medicine, University of Nairobi, P. O. Box 19701-00202, Nairobi, Kenya. Email: goyoo@uonbi.ac.ke

\section{ABSTRACT}

Objective: To determine Health Related Quality Of Life (HRQOL) profiles of patients with Rheumatoid Arthritis (RA).

Design: Prospective, cross-sectional study.

Setting: Ambulatory out-patient clinics of Kenyatta National Hospital (KNH), a public national referral hospital.

Subjects: Of the 180 patients interviewed and examined, 60 met the American College of Rheumatology (ACR) diagnostic criteria for RA.

Results: Of the 60 patients recruited, $58 \%$ of study patients had physical component HRQOL scores ranging from poor to fair, compared to $65 \%$ who had mental component HRQOL scores ranging from good to very good. Both physical and mental health HRQOL summary scores showed significant negative correlations with disease activity (DAS-28) scores ( $<0.001$ for both) among the study patients. The HRQOL physical health summary scores were significantly better in the 28 study patients who were on treatment with at least one DMARD (mean score $67.25 \pm 18.17$ ) than in the other 28 study patients who had not been on DMARD therapy (mean score $53.93 \pm 18.55), p=0.008$. The trend was similar but less prominent with mental health QOL summary scores, with means of $75.11 \pm 19.19$ with DMARDs, and $62.29 \pm 21.85$ without DMARDs $(p=0.034)$. There was a significant association between consistency of treatment with any drug and QOL physical health summary scores, with mean score for patients consistently on treatment $(65.16 \pm 19.26)$ being much better than for those on intermittent drug treatment $(50.94 \pm 16.27), p=0.009$. These associations were similar for QOL mental health summary scores but did not reach significance.

Conclusions: In this population of ambulatory patients with RA, physical component HRQOL ranged from poor to fair, while mental component HRQOL ranged from good to very good in the majority of patients. Severity of disease showed a strong negative association with HRQOL among the study patients, while DMARD therapy and adherence to drug treatment showed a positive association with HRQOL. Improved and better adherence to DMARD therapy with resultant decrease in disease activity is likely to result in improved HRQOL in this population of patients with RA.

\section{INTRODUCTION}

Rheumatoid Arthritis (RA) is a chronic systemic autoimmune inflammatory disorder characterized by deforming symmetrical polyarthritis of varying extent and severity, associated with synovitis of joint and tendon sheaths, articular cartilage loss, erosion of juxta-articular bone and, in most patients, the presence of IgM rheumatoid factor in the blood. In some patients systemic and extra-articular features may be observed during the course of the disease and, rarely, prior to onset of joint disease. These include anaemia, splenomegally, weight loss, vasculitis, serositis, mononeuritis multiplex, interstitial inflammation in the lungs and exocrine salivary and lacrimal glands, as well as nodules in 
subcutaneous, pulmonary and scleral tissue (1). Rheumatoid arthritis is a disease with regional variation in prevalence, severity, age at onset and female to male ratio of patients affected (117). Except for west Africa where the incidence of rheumatoid arthritis has remained low and the disease is mild (1), studies in the rest of Africa have recorded increasing prevalence and, in some cases, increasing severity of the disease (3-14). Quality of life issues are of great importance in RA since it is a disease that is progressively debilitating in many ways such as life long pain, progressively worsening physical disability and deformities, yet few studies have been documented from Africa in this regard. Patients with RA are condemned to a life of obligatory dependence on expensive drugs with harmful side effects for temporary relief of pain and to retard the progressive physical disability. Such patients who are still in employment are faced with the bleak prospect of loss of such employment and hence loss of income, social status, social support, independence, and social distraction (1). Patients with RA also have a significantly higher level of comorbid conditions, especially infections and cardiovascular disease (1). RA therefore affects negatively all aspects of quality of life such as physical functioning, social functioning, emotional functioning, mental health, and general health (18). Functional capacity, as studies have shown, is strongly influenced by disease activity throughout the course of RA. Use of DMARDs together with NSAIDs therefore impact positively on quality of life in patients with RA (19). Over the past 20 years various instruments called Health Related Quality Of Life (HRQOL) patient questionnaires, both generic and specific, have been developed and used for assessing the effects of RA on various aspects of the patients life $(19,20)$. Such assessments are carried out as baseline, and subsequently at regular intervals, to monitor the effects of treatment on the activity of the disease, quality of life, and functional capacity.

Assessing patient-centered outcomes in RA has become a high priority for patients and providers, particularly in the light of newer and more effective treatment options aimed at maintaining good functional capacity. Currently there is no single clinical or laboratory variable that can completely measure disease activity or treatment response, but HRQOL questionnaires have been shown in studies to give a more accurate assessment of the patients disease, functional status, and well being $(21,22)$. Newer HRQOL instruments continue to be developed, which are both multi-dimentional and diseasespecific with additional discriminant validity, to meet the emerging realities of RA and its treatment in the 21 st century (23). The instruments selected for use in this study, however, are among the most widely used in rheumatology to date because of their reliability, validity, sensitivity, and responsiveness to change (20). These are the SF-36 and DAS-28.

\section{MATERIALS AND METHODS}

Study population: The study was conducted on patients attending the medical outpatient clinic at Kenyatta National Hospital which is the national referral health institution located in Nairobi, the capital city of the republic of Kenya.

Patient recruitment: Memos to clinicians soliciting for patients were posted in various departments at the KNH. Patients referred for the study with established or suspected diagnosis of RA (defined according to the ACR 1987 revised criteria) were screened consecutively. All patients of both sexes aged thirteen years and above, with own or legal guardian's signed consent, who also met the ACR criteria for classification of RA were recruited. All recruited patients had their ages, sexes, employment status, level of education and medical treatment history recorded by the investigator on an already prepared questionnaire. Each of these patients was then physically examined, followed by an assessment of severity of disease and HRQOL using DAS-28 and SF-36 respectively. This information was also recorded on a prepared data sheet by the investigator.

Laboratory methods: A CELDYN 3200 series coulter machine was used for FBC, and Wintrop method for ESR determinations. Normal ESR by this method are $0-20 \mathrm{~mm} / \mathrm{hr}$ and $0-9 \mathrm{~mm} / \mathrm{hr}$ for females and males respectively. IgM rheumatoid factor was determined using RA LATEX TEST, which is a standard latex agglutination test with both negative and positive controls. With this test the presence of agglutination indicates a level of RF in the sample equal to or $>8 \mathrm{I} . \mathrm{U} / \mathrm{ML}$, while a negative result indicates a level of RF in the sample of $<8$ I.U / ML. Blood for RF test was only drawn from those patients without a previous positive RF test result.

Ethical considerations: The study was done after receiving consent from the $\mathrm{KNH}$ ethical and research committee, and was only carried out on adult patients who had given informed consent or those 
below the age of 18 years only with informed consent of their parents or legally recognized guardians.

Data analysis: Data was analyzed using SPSS computer software package. Continuous variables were categorized in ranges and summarized into means, medians, modes, and standard deviations. Quantitative data was presented in frequency distribution tables and bar diagrams. Relationships between two continuous variables, for example HRQOL and age, HRQOL and duration of illness, HRQOL and DAS-28, were analyzed by Pearson correlation coefficients (if variables normally distributed) or by Spearman rank correlation (if variables not normally distributed). Relationships between continuous variables and categorical data, for example HRQOL and gender, or HRQOL and employment status were analyzed by t-test method (if variables normally distributed) or by MannWhitney $\mathrm{U}$ test (if variables not normally distributed), while that between QOL and type of drug treatment or level of education were analyzed using one way ANOVA (if variables normally distributed) or KruskalWallis one way ANOVA (if variables not normally distributed). A significant association was deemed present at a $p$ value of $<0.05$.

\section{RESULTS}

Of the 180 patients aged thirteen years and above who were screened for rheumatoid arthritis between September 2005 and April 2006, sixty satisfied the inclusion criteria and were recruited for the study. Fifty-eight percent of study patients had physical component $\mathrm{HRQOL}$ scores ranging from poor to fair compared to $65 \%$ who had mental component HRQOL scores ranging from good to very good. The percentage distributions of physical component (pc) and mental component (mc) HRQOL summary scores for the study patients are as illustrated in Figure 1.

\section{Figure 1}

Distribution of HRQOL categories among the study patients

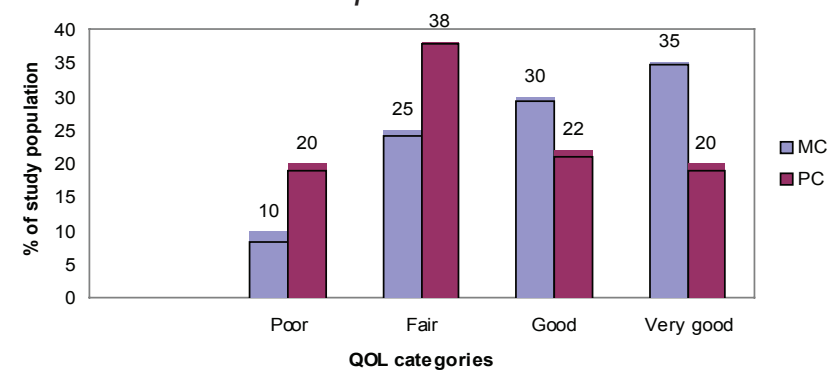

KEY: HRQOL scores were categorized as: 0-40 (poor), 41-60 (fair), 61-80 (good), 81-100 (very good). $P C=$ Physical component; $M C=$ Mental Component .
Figure 2

Correlation between HRQOL physical health summary scores and DAS-28 scores in the study patients

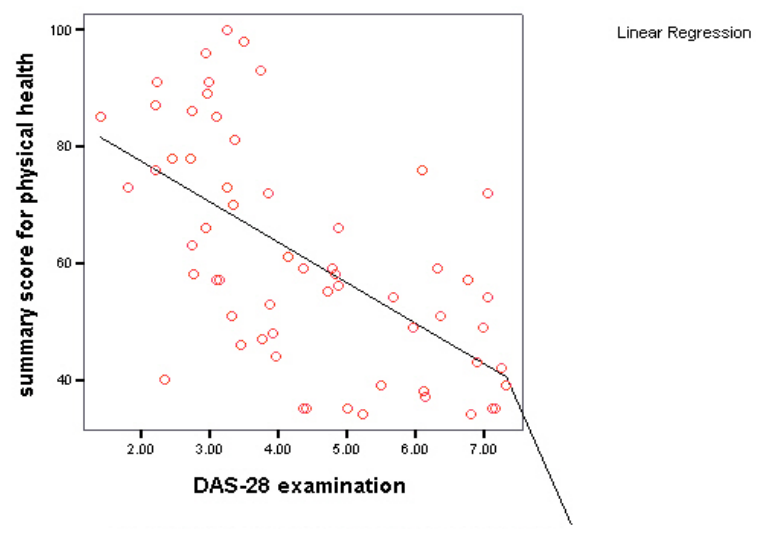

Summaryscore for physical health $=91.32+-6.95^{*}$ das R-Square $=0.36$

Figure 3

Correlation between HRQOL summary scores for mental health and DAS-28 scores in the study patients

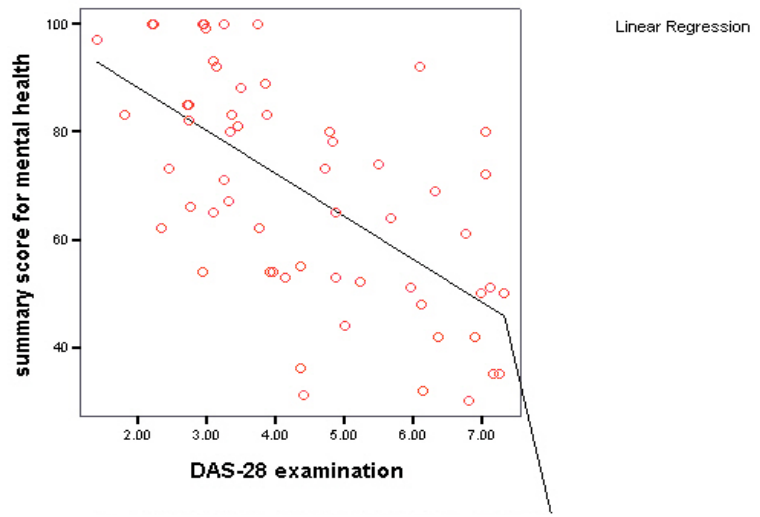

Summaryscore for mental health $=104.11+-7.97^{*}$ das $\mathrm{R}$-Square $=0.40$

There was no significant association between HRQOL summary scores and level of education ( $p$ values of 0.79 and 0.30 for physical and mental components respectively), employment status ( $p=$ 0.73 and $p=1$ for physical and mental components respectively), duration of illness ( $p=0.155$ and $p=0.435$ for physical and mental components respectively) and patient's age ( $p=0.617$ and $p=0.193$ for physical and mental components respectively) in the study subjects. Both physical and mental health HRQOL summary scores however showed significant negative correlations with disease activity scores (Pearson correlation coefficients of -0.603 and -0.632 respectively, $p<0.001$ for both) among the study patients as illustrated in Figures 2 and 3 respectively.

The HRQOL physical health summary scores 
were significantly better in the 28 study patients who were on treatment with at least one DMARD [mean score $67.25 \pm 18.17$ ] than in the other 28 study patients who had not been on DMARD therapy [mean score $53.93 \pm 18.55$ ], $p=0.008$. The trend was similar but less prominent with mental health QOL summary scores, with means of $75.11 \pm 19.19$ with DMARDs, and $62.29 \pm 21.85$ without DMARDs $(p=$ 0.034). There was a significant association between consistency of treatment with any drug and QOL physical health summary scores, with mean score for patients consistently on treatment $(65.16 \pm 19.26)$ being much better than for those on intermittent drug treatment $(50.94 \pm 16.27), p=0.009$. These associations were similar for QOL mental health summary scores but did not reach significance, with mean scores of $72.00 \pm 20.50$ for consistent treatment and $61.72 \pm 22.07$ for intermittent treatment, $\mathrm{p}=$ 0.097. The relationship between DMARD therapy and QOL summary scores in the study patients is summarized in Table 1, while that between consistency of treatment and QOL summary scores is summarized in Table 2.

Table 1

Relationship between DMARD therapy and mean QOL summary scores in the study patients

\begin{tabular}{llllllc}
\hline QOL Category & $\begin{array}{l}\text { DMARD } \\
\text { treatment }\end{array}$ & No. & Mean score & $\begin{array}{c}\text { Standard } \\
\text { deviation }\end{array}$ & Median & $\begin{array}{c}\text { Asymp. (2-tailed) } \\
\text { p-value }\end{array}$ \\
summary score & Yes & 28 & 67.25 & 18.17 & 63.50 & 0.008 \\
for physical health & No & 28 & 53.93 & 18.55 & 51.00 & \\
\cline { 2 - 6 } & Total & 56 & 60.59 & 19.39 & 57.00 & \\
\cline { 2 - 6 } Summary score for & Yes & 28 & 75.11 & 19.19 & 76.00 & \multirow{2}{*}{0.034} \\
mental health & No & 28 & 62.29 & 21.85 & 58.50 & \\
\cline { 2 - 5 } & Total & 56 & 68.70 & 21.38 & 68.00 & \\
\hline
\end{tabular}

Table 2

Relationship between consistency of treatment and mean QOL summary scores in the study patients

\begin{tabular}{|c|c|c|c|c|c|c|}
\hline QOL Category & $\begin{array}{l}\text { Consistency } \\
\text { of treatment }\end{array}$ & No. & Mean score & $\begin{array}{l}\text { Standard } \\
\text { Deviation }\end{array}$ & $\begin{array}{l}\text { Median } \\
\text { Score }\end{array}$ & $\begin{array}{l}\text { Asymp.(2-tailed) } \\
p \text {-value }\end{array}$ \\
\hline $\begin{array}{l}\text { summary score } \\
\text { for physical health }\end{array}$ & $\begin{array}{l}\text { Regular } \\
\text { Intermittent } \\
\text { Total }\end{array}$ & $\begin{array}{l}38 \\
18 \\
56\end{array}$ & $\begin{array}{l}65.16 \\
50.94 \\
60.59\end{array}$ & $\begin{array}{l}19.26 \\
16.27 \\
19.40\end{array}$ & $\begin{array}{l}59.00 \\
48.50 \\
57.00\end{array}$ & 0.009 \\
\hline $\begin{array}{l}\text { summary score } \\
\text { for mental health }\end{array}$ & $\begin{array}{l}\text { Regular } \\
\text { Intermittent } \\
\text { Total }\end{array}$ & $\begin{array}{l}38 \\
18 \\
56\end{array}$ & $\begin{array}{l}72.00 \\
61.72 \\
68.70\end{array}$ & $\begin{array}{l}20.50 \\
22.07 \\
21.38\end{array}$ & $\begin{array}{l}70.00 \\
57.50 \\
68.00\end{array}$ & 0.097 \\
\hline
\end{tabular}

Table 3

DMARD compared to NSAID therapy in relation to DAS-28 and QOL summary scores in the study population

\begin{tabular}{lllll}
\hline $\begin{array}{l}\text { Type of } \\
\text { treatment }\end{array}$ & & $\begin{array}{l}\text { DAS-28 } \\
\text { examination }\end{array}$ & $\begin{array}{l}\text { Physical } \\
\text { health scores }\end{array}$ & $\begin{array}{l}\text { Mental } \\
\text { health scores }\end{array}$ \\
\hline DMARDs & No. & 28 & 28 & 28 \\
& Mean & 4.2271 & 67.25 & 75.11 \\
& $\begin{array}{l}\text { Std. Deviation } \\
\text { Median }\end{array}$ & 1.6051 & 18.171 & 19.186 \\
& 3.4700 & 63.50 & 76.00 \\
NSAIDs & No. & 15 & & \\
& Mean & 4.9787 & 45 & 15 \\
& Std. Deviation & 1.65845 & 15.941 & 60.67 \\
Asymp. (2-tailed), p- value & 0.108 & 44.00 & 54.00 \\
\hline
\end{tabular}


The mean disease activity score for those study patients who were on NSAIDs alone (4.98) was higher than that for those on DMARD therapy (4.23), but the difference was not significant $(p=0.108)$. On the other hand those on NSAIDs alone had significantly worse QOL summary scores, for both mental and physical health, than patients on DMARDs ( $p=0.002$ and $p=0.039$ for physical and mental health summary scores respectively) as summarized in Table 3.

There was no significant difference between those study patients on prednisone compared to those on DMARDs with regards to QOL and disease activity scores. Only one patient, a female, out of the sixty study patients had undergone corrective surgery for complications of rheumatoid arthritis. She had been done bilateral hip joint replacement surgery and corrective surgery for a badly damaged left knee joint. Thirteen of the study patients had been on physiotherapy; three on occupational therapy and one had psychiatric management. A total of twenty out of the sixty study patients had various co-morbid conditions as presented in Table 4. The most common co-morbidity was arterial hypertension, accounting for 11 out the 20 , followed by peptic ulcer disease ( 5 patients) and diabetes mellitus (2 patients).

Table 4

Co-morbid conditions among the study patients

\begin{tabular}{lcc}
\hline $\begin{array}{l}\text { Co-morbid } \\
\text { conditions }\end{array}$ & Frequency & Percent \\
\hline HTN & 6 & 10.0 \\
PUD & 3 & 5.0 \\
eye cataract & 1 & 1.7 \\
PTB & 1 & 1.7 \\
skin lesions & 1 & 1.7 \\
HHD & 1 & 1.7 \\
fibroids & 1 & 1.7 \\
asthma & 1 & 1.7 \\
HTN \& PUD & 2 & 3.3 \\
HTN \& DM & 2 & 3.3 \\
Anaemia & 1 & 1.7 \\
Total & 20 & 33.4 \\
Total & 60 & 100.0 \\
\hline
\end{tabular}

\section{DISCUSSION}

Fifty-eight per cent of study patients had physical component QOL scores ranging from poor to fair, compared to $65 \%$ who had mental component QOL scores ranging from good to very good. This would imply that the physical disability attendant on rheumatoid arthritis in this patient population, probably due to some coping mechanism or effective social support, was not necessarily translated into psychological distress. Both component scores showed no significant association with age, level of education, employment status, or duration of illness among the study patients. Though this tends to diminish any possible confounding effects of these socio-demographic factors, one would have expected unemployment and low level of education, as markers of low socio-economic status, to be associated negatively with the QOL summary scores among the study patients. Similarly the lack of association between $\mathrm{QOL}$ and duration of illness is unexpected since functional capacity, and therefore $\mathrm{QOL}$, is expected to deteriorate with time (19). The lack of association could probably be due to a short median duration of illness of only 24 months recorded in this study. At such a relatively early stage, disease activity rather than accrued joint damage would be expected to be the major determinant of functional capacity and hence QOL.

Both physical and mental health QOL summary scores however showed significant negative correlations with disease activity scores [Pearson correlation coefficients of -0.603 and 0.632 respectively, $p<0.001$ for both] among the study patients. This is an expected association since disease activity is the critical determinant of functional capacity, hence $\mathrm{QOL}$, throughout the course of rheumatoid arthritis (19). Achieving disease remission by improved use of DMARD in this patient population is therefore likely to result in better HRQOL. The better HRQOL associated with compliance with medication and use of glucocorticoids or DMARDs, compared to intermittent medication or use of NSAIDS alone, as seen in this study tends to emphasize the need for consistent use of DMARDs and / or glucocorticoids rather than NSAIDs alone in the drug treatment of rheumatoid arthritis.

There is documented evidence that functional capacity, and therefore $\mathrm{QOL}$, in RA patients is influenced by multiple variables. The variables most frequently suggested are disease activity, joint destruction, and psycho-social characteristics of each individual patient [19]. Studies have further shown that whereas disease activity is a strong determinant of functional capacity throughout the course of RA, the contribution from joint destruction becomes increasingly important with time, and is the main determinant of functional capacity later in 
the disease course (24). Achieving maximal control of both disease activity and joint destruction early in the disease by use of Disease Modifying Anti-Rheumatic Drugs (DMARDs) is thus of great importance in improving $\mathrm{QOL}$ throughout the course of RA.

\section{ACKNOWLEDGEMENTS}

To the KNH director's office and the Ethical Review Committee for approving the study. The KNH-MOPC nursing staff for assisting with the recruitment of patients, and to the patients for accepting to participate in the study.

\section{REFERENCES}

1. Warrell D.A., Cox T.M., Firth J.D., et al. Oxford Textbook of Medicine. Fourth Edition. New York. Oxford University Press Inc. 2003.

2. Kavita G., John J.N., Sarjoo M.B., et al. E-Med update on RA. 2004; 1-20.

3. McGill P. RA in sub-saharan Africa. Ann. Rheum. Dis. 1991; 50: 965-966.

4. Gefland M. The Sick African. A clinical study. Cape Town. Juta. 3rd ed 1957; 8-9.

5. Goodall J. W. D. Joint swellings in Africans. Central Afr. J. Med. 1956; 2:220-223.

6. Shaper A. G. and Shaper. L. Analysis of medical admissions to Mulago Hospital. East Afr. Med. J. 1957; 25: 647-678.

7. Greenwood B. M. Polyarthritis in Western Nigeria. 1. Rheumatoid arthritis. Annals Rheum. Dis. 1969; 28: 488-496.

8. Harries J. R. Rheumatoid nodules in an African. East Afr. Med. J. 1962; 39:69-70.

9. Hall L. Polyarthritis in Nairobi Africans. East Afr. Med. J. 1963; 4: 354-358.

10. Kanyerezi B. R., Baddely $H$. and Kisumba D. Rheumatoid arthritis in Ugandan Africans. Annals Rheum. Dis. 1970; 29: 617-621.
11. Kanyerezi B. R. Some aspects of Rheumatoid disease in Uganda. East Afr. Med. J. 1980; 57: 39-43.

12. Adebajo O. A, and Reid D.M. Rheumatoid arthritis in a West African and British teaching hospital in 1987. Br. J. Rheumatol. 1988; 27:Suppl. 1.

13. Bagg L.R., Hansen D.P., Lewis C., et al. RA in Kenya. I. Clinical observations. Ann. Rheum. Dis. 1979; 38: 2325.

14. Beighton P., Solomon L. and Valkenburg H.A. Rheumatoid arthritis in a rural South African Negro population. Ann. Rheum. Dis.1957; 34: 136-141.

15. Thould A. K. and Simon G. Assessment of radiological changes in the hands and feet in rheumatoid arthritis. Ann. Rheum. Dis. 1966; 25; 220-228.

16. Chikanza I. C., Stein M., Lutalo S., et al. The clinical, serologic, and radiological features of RA in ethnic black Zimbabwean and British Caucasian patients. J. Rheum. 1994; 21: 2011-2015.

17. McGill P.E. and Oyoo G.O. Rheumatic disorders in subsaharan Africa. East Afr. Med. J. 2002; 79; 214-216.

18. Chorus A.M.J., Miedema H.S., Boonen A., et al. Quality of life and work in patients with RA and AS of working age. Ann. Rheum. Dis. 2003; 62: 1178-1184.

19. Droassaer-Bakker K.W., Debuck M., Vanzeben D., et al. Long term course and outcome of functional capacity in RA. Arth. Rheum. 1999; 42:1854-1860.

20. American College of Rheumatologists, patient outcomes in rheumatology- a review of measures. Arthr. Rheum. 2003; 49: S1- S232.

21. Chiou F.C., Sherbourne C.D., Ofman J., et al. Development and validation of Cedars-Sinai HealthRelated Quality of Life in RA [CSHQ-RA] short form instrument. Arthr. Rheum. 2004; 51: 358-364.

22. Russak S.M., Croft J.D., Furst E.D., et al. The use of RA Health-Related Quality of Life patient questionnaires in clinical practice: lessons learned. Arthr. Rheum. 2003; 49: 574-584.

23. Russak S.M., Sherbourne C.D., Lubeck D.P., et al. Validation of a RA Health-Related Quality of Life Instrument, the CSHQ-RA. Arthr. Rheum. 2003; 49: 798-808

24. James R. O. and Dell, M. D, Therapeutic strategies for RA. N. Engl. J. Med. 2004; 350: 2592. 